\title{
Psicologia e ontologia: fundamentos para uma reflexão crítica sobre a produção de conhecimento
}

\author{
Tadeu Mattos Farias* (i) \\ Herculano Ricardo Campos $\mathbb{1}$ \\ Universidade Federal do Rio Grande do Norte, Natal, RN, Brasil
}

\begin{abstract}
Resumo: Problematizamos a prática científica na psicologia e apresentamos elementos teóricos que possibilitam uma crítica ontológica a esse campo. Consideramos que falta à produção de conhecimento psicológico uma concepção ontológica sobre a sociedade, o agir humano e a produção do conhecimento, secundarizando a investigação e o debate a respeito do que é o próprio ser sobre o qual o conhecimento se debruça. Concluímos afirmando que tal postura resulta no aprofundamento das divergências entre as diferentes escolas da psicologia, notadamente de objeto e de método, e que é necessário aprofundar a análise no sentido de desvelar a concepção de ser humano que subjaz às diferentes escolas, criticando-a tendo em vista o sujeito concreto com o qual se lida nos diferentes contextos sociais.
\end{abstract}

Palavras-chave: ciência, ontologia, psicologia.

\section{Introdução}

A realidade humana é uma totalidade histórica, dinâmica e articulada, em que o campo da produção do conhecimento está intimamente relacionado à dinâmica social e seus recortes históricos. À ciência, complexo articulado à totalidade social, entendida como modalidade da práxis, é inerente a reflexão sobre pressupostos, procedimentos, resultados, usos, de modo tal que se revela impossível a dissociação entre Filosofia e Ciência, esta sem aquela. A própria negação de tal imbricação "constitui determinada postura filosófico-metodológica" (Shuare, 2017, p. 21).

Nessa direção, identificamos como um problema central no debate sobre a produção de conhecimento em psicologia a falta de uma concepção ontológica sobre a sociedade, o agir humano e a produção do conhecimento, ou mesmo o ocultamento de tais fundamentos presentes nas diversas vertentes teórico-metodológicas sob a ideia de uma negação da ontologia. Entendemos, igualmente, que $\mathrm{o}$ antiontologismo e o veto à crítica dos fundamentos, mesmo nas posições que se supõem contra-hegemônicas, são uma das formas da identificação do projeto científico da psicologia com a reprodução da ordem do capital.

Aqui, problematizamos a prática científica no campo da psicologia partindo de uma reflexão sobre o solo histórico em que se desenvolve como campo científico, período caracterizado como de "decadência ideológica" do pensamento burguês (Lukács, 2018), analisando alguns desdobramentos para a constituição de suas tendências

*Endereço para correspondência: tadeu.farias@gmail.com, herculanorcampos@, gmail.com ontoepistemológicas fundamentais, e expomos alguns elementos teóricos que possibilitam uma crítica ontológica a esse campo.

\section{Psicologia e decadência ideológica: hegemonia e pluralidade epistemológica}

É reconhecida a pluralidade teórica e, por conseguinte, epistemológica da psicologia. Com o reconhecimento de tal pluralidade está o diagnóstico de "crise permanente" da área (Cornejo, 2005). A principal implicação de tal diagnóstico na psicologia, ou mesmo nas Ciências Sociais, seria a emergência de novos paradigmas (ou da noção contemporânea de paradigmas em Ciências Sociais), crenças sobre o mundo e sobre o conhecimento, as quais somente admitem a crítica em seus próprios termos e jamais por outras crenças/ paradigmas. Partimos do entendimento de que a defesa de uma espécie de "pacto de não agressão" e a aceitação acrítica da multiplicidade epistemológica, como está posto no cenário atual da produção de conhecimento - não só no campo da psicologia -, obstrui justamente o potencial crítico, e por isso emancipatório, da ciência.

Contudo, ao mesmo tempo em que é efetivado o bloqueio da crítica de um paradigma por outro, uma vez que são "linguagens" diferentes, fica evidenciado que a única possibilidade de confrontação seria em termos ontológicos, ou seja, confrontando a forma como distintos paradigmas figuram, concebem o mundo (Duayer, 2015). Visto que qualquer proposta teórico-metodológica possui uma figuração de mundo que a sustenta, mesmo quando se colocam como antiontológicas (Lacerda, 2010), 
a análise crítica dos fundamentos se apresenta como questão fundamental para as Ciências Sociais.

Consideramos, então, não apenas que a crítica é possível, como é fundamental: ela é o próprio modo de conhecer das Ciências Sociais. E crítica, nesse sentido, é crítica ontológica (Duayer, 2016), que por ora definiremos como crítica às figurações de mundo que estão na base de cada paradigma ou teoria.

$\mathrm{Na}$ história da psicologia, conforme as sistematizações realizadas por Figueiredo (2008) e Cornejo (2005), se por um lado se consolidou um modelo hegemônico de ciência que se referencia nas Ciências Naturais e seu método, por outro se efetivaram propostas alternativas que formam um caleidoscópio paradigmático cujo cerne é, a partir de diferentes entendimentos acerca do objeto, fazer frente aos limites que a influência positivista impõe ao entendimento do ser humano. Se as tradições influenciadas pelo positivismo renegam a reflexão ontológica em nome da busca pelas leis que regem o comportamento humano empiricamente acessíveis, a atitude corrente nas tradições hermenêuticocompreensivas (Cornejo, 2005) é a de que o conhecimento do mundo não pode ser objetivo, uma vez que seria sempre descrito de um ponto de vista (pessoal-experiencial, teórico, de classe, cultural, étnico) (Duayer, 2016).

A ausência da reflexão ontológica está na origem mesma do projeto de psicologia científica desenvolvido por Wundt (Araújo, 2007). Ele aplicou nesse empreendimento as teses da sua teoria do conhecimento, de base kantiana, e por isso de viés empirista, gnosiológico e antiontológico, como uma evidente tentativa de excluir dessa disciplina científica os conhecimentos que são fruto da especulação filosófica.

Para situar criticamente tanto o empreendimento Wundtiano quanto - e sobretudo - os caminhos posteriores da psicologia como ciência, nos valemos da interpretação de Lacerda (2010), para quem as características que assume a psicologia como ciência e a própria emergência de um projeto de psicologia como disciplina científica, são tributárias do que Lukács (2018) chamou de período de "decadência ideológica" da burguesia. Ou seja, a psicologia é uma das expressões, entre tantas, do trânsito da burguesia de uma classe revolucionária para uma classe que, vitoriosa na luta contra a aristocracia feudal, se torna dominante e passa a ter como principal ameaça a classe trabalhadora, tendo nas revoluções de 1848 o marco definitivo.

Nesse trânsito, no plano da reflexão teórica, à burguesia deixa de interessar a profunda investigação da realidade e de suas contradições, e tomar o mundo sob o domínio da razão. A característica central da decadência ideológica é a apologética da realidade instituída pela ordem capitalista, e sua função é "garantir a reprodução social da ordem vigente e fazer com que a contribuição do conhecimento se reduza à intensificação do processo de valorização do capital" (Lacerda, 2010, p. 65).

De acordo com Coutinho (2010), há duas formas de manifestação fundamentais de tal decadência: o agnosticismo e o irracionalismo. A determinação central do racionalismo agnóstico é que, em certos estágios do desenvolvimento capitalista, há um sentimento de segurança e estabilidade resultante do próprio desenvolvimento das forças produtivas. Como expressão disso, a razão é limitada, burocratizada, e o empreendimento científico passa a ser a formulação de leis universais e imutáveis, apoiadas em regras metodológicas formais e a partir de ciências compartimentadas, que fragmentam a totalidade do real e se reduzem a uma manipulação da realidade aparente. Desaparecem dos fenômenos suas contradições, condições de gênese histórica e sua essência social. O positivismo, o neopositivismo e o estruturalismo são distintas expressões deste agnosticismo, da "miséria da razão" (Coutinho, 2010; Lacerda, 2010).

Por seu turno, o irracionalismo é determinado pelos contextos de crise do capitalismo e pelo espraiamento de um sentimento de angústia, pessimismo e ceticismo diante do real e das possibilidades de sua apreensão racional e transformação consciente (Coutinho, 2010; Lukács, 2020). Daí concepções aversas à cognoscibilidade do real e à própria razão. $\mathrm{O}$ irracionalismo se volta contra $\mathrm{a}$ realidade social e contra o racionalismo agnosticista, mas encontrando na intuição a única fonte de conhecimento, resultando em subjetivismo, particularismo e numa crítica romântica à ordem, o que por sua vez resulta em uma forma de apologia indireta desta mesma ordem. É nesse sentido que Lukács (2020) vai afirmar que "não existe visão de mundo inocente" (p. 10), quer seu formulador tenha consciência ou não dos efeitos apologéticos de suas concepções, e que não se deve julgar a intenção de um teórico, mas "a expressão objetivada do pensamento e sua eficácia historicamente necessária".

A psicologia como ciência é expressão, justamente, dos caminhos da decadência ideológica burguesa (Lacerda, 2010), ao menos nos termos que foram predominantes em sua constituição e desenvolvimento. A partir de meados do século XIX, os impulsos de um campo de reflexão racional sobre a autoatividade humana, sobre a natureza do ser humano responsável por construir sua própria história, que estiveram presentes ao longo do período revolucionário da burguesia, cedem espaço para uma ciência parcial e voltada para controle do ser humano com vistas à manutenção da ordem social estabelecida e em consonância com os interesses da nova classe dominante.

Essa questão já se expressa no projeto de Wundt, todavia a afirmação definitiva do campo específico e de seu caráter apologético se dá na apropriação em solo estadunidense dessa ciência em gênese, quando a psicologia precisou responder às necessidades tecnicistas, às demandas por uma ciência útil e às exigências cientificistas que pudessem lhe garantir o estatuto de ciência independente. Em torno da quantificação, a psicologia ganhou estatuto de ciência e, em que pese toda a pluralidade do campo, formou uma linha hegemônica que terá no behaviorismo sua primeira expressão madura do agnosticismo: "O tecnicismo substituiu a teoria enquanto 
critério último para julgar o valor e a aceitabilidade das pesquisas psicológicas" (Lacerda, 2010, p. 144).

Por outro lado, esse período também solidifica tendências irracionalistas, nascidas em uma Europa em crise, que irão influenciar a psicologia e buscarão antagonizar com esse projeto hegemônico, contudo estabelecendo projetos igualmente antiontológicos, seja sob influência da filosofia de Nietzsche, da fenomenologia, do existencialismo etc. Enfim, quer seja pelo caminho do agnosticismo ou pelo irracionalismo, a pluralidade epistemológica da psicologia passa ao largo da ontologia, da investigação dos fundamentos da realidade humana sob a ordem social burguesa e, de forma triunfalista ou pessimista, pelo formalismo objetivista ou pelos diversos subjetivismos, acaba constituindo formas de produção de conhecimento que capitulam diante da sociabilidade capitalista.

Em decorrência, a psicologia se constituiu e se desenvolveu como um complexo de orientações intelectuais muitas vezes contraditórias entre si, sem que as diferenças que as enformam sejam analisadas e confrontadas nos seus fundamentos. Entendemos que a interpretação científica é uma forma de atividade do ser humano social e que, portanto, o conhecimento científico é um tipo de trabalho, uma expressão da relação entre o ser humano e a natureza plasmada na história (Vygotski, 2013), de modo que consideramos a possibilidade do debate e da confrontação das concepções a partir da explicitação dos seus condicionantes históricos.

Em outras palavras, entendemos ser possível e necessário caminhar na direção da conscientização, para usar um termo que Martin-Baró (1986/2011) emprestou de Freire, a respeito do quê, do por que e do para quê das diferentes perspectivas de construção do conhecimento e da prática na/da psicologia. Nesse sentido, apresentamos os parâmetros com base nos quais propomos o debate. Nossa análise se volta para os caminhos mais consolidados da área e nosso foco específico está na ontologia e na crítica ontológica.

Nessa direção, a discussão que propomos parte do ser social (forma de ser própria do ser humano). A partir da análise dessa forma específica de ser, pretendemos demonstrar que a negação da ontologia é uma característica que une o positivismo a várias correntes epistemológicas que buscam criticá-lo/superá-lo.

\section{Ontologia do ser social e práxis científica}

Nosso ponto de partida é justamente a consideração daquilo que é tomado como objeto da psicologia, o ser humano. Para este momento do texto, interessam-nos especificamente as implicações que a concepção do ser humano possa ter para a questão do conhecer.

Partimos da formulação de Marx e Engels (2007) de que o "primeiro pressuposto de toda a existência humana e também, portanto, de toda a história" é "o pressuposto de que os homens têm de estar em condições de viver para poder "fazer história"' (p. 32-33). Em outros termos, se o ser humano precisa (sobre)viver para, por exemplo, desenvolver a linguagem, então precisa, antes de mais nada, produzir os meios para satisfazer as necessidades que garantam sua sobrevivência. Portanto os demais complexos da vida humana têm como condição necessária que os seres humanos transformem a natureza para produzir as condições de sua reprodução como seres humanos, ou seja, trabalhem ${ }^{1}$.

A transformação da natureza requer que os seres humanos se articulem coletivamente, em relações sociais de produção, o que implica consciência e linguagem. Por esse motivo, há uma prioridade ontológica do trabalho em relação aos outros traços humanos, que não se traduz em termos cronológicos (o que veio primeiro?), mas apenas no fato de que estes pressupõem aquele para existirem, "todas as outras categorias dessa forma de ser têm já, em essência, um caráter puramente social" (Lukács, 2013, p. 43).

Mais importante que isso é o fato de que é o trabalho que permite ao ser humano um salto - qualitativo - em relação à forma antecedente de ser (biológico), sem jamais se separar completamente desta; a partir daí as características desse ser são definidas na articulação de processos históricos, afastando-se das barreiras naturais. Assim, devemos olhar com mais atenção para as especificidades desse ser e para os desdobramentos - sempre históricos - dessas especificidades.

$\mathrm{O}$ trabalho, por ser o elemento fundante do ser social, é modelo geral para o agir humano (Lukács, 2013). Assim, as características que assume no agir humano nos interessam para a compreensão tanto do ser humano quanto da prática científica - enquanto prática humana. É possível destacar três aspectos característicos do agir humano enquanto trabalho (Lukács, 2013; Marx, 2013; Medeiros, 2013): (a) trata-se de agir intencional. Como estamos tratando da realização de um fim determinado (satisfação de uma necessidade), ou seja, um agir teleológico, essa ação parte de um propósito predeterminado na consciência; (b) contudo não se pode realizar a finalidade posta agindo a partir do nada, com nada e sobre nada. Age-se sobre algo (natureza, pessoas, estruturas sociais), transformando-o para que se alcance o objetivo posto; (c) nesse processo, o sujeito faz escolhas entre alternativas.

Ao longo desse processo que constitui ontologicamente o agir humano, o sujeito precisa investigar os meios adequados para alcançar a finalidade estabelecida/posta. Como condição de tal investigação está um "conhecimento objetivo da gênese causal das objetividades e dos processos cujo andamento pode levar a alcançar o fim posto" (Lukács, 2013, p. 54). É necessário

1 Trabalho, nesse sentido, está sendo apresentado em seu caráter fundante, ontológico, e ainda sem qualquer determinação das formas históricas específicas sob as quais ele aparece. Por exemplo, não falamos aqui de trabalho sob relações de produção capitalistas (trabalho assalariado e estranhado), relações estas que transformam a capacidade do ser humano produzir bens para a satisfação de necessidades em mercadoria. 
descobrir as legalidades, propriedades, conexões, que governam os objetos sobre os quais se debruça o sujeito e também novas possibilidades de conexão, de combinação, presentes neles, formas pelas quais, se efetivadas na ação do sujeito, a finalidade deve ser alcançada.

Visto que os objetos do mundo operam de forma absolutamente indiferente às necessidades humanas, quem toma esses objetos e suas características a partir de seu ponto de vista e suas necessidades é o sujeito que trabalha; quem vê a possibilidade de uma faca em uma pedra é o sujeito (não há finalidade na natureza). Contudo o sujeito não pode fazer algo que está além das possibilidades do objeto, ele precisa descobrir as características do objeto que permitam transformá-lo em instrumento. Quando faz isso, quando transforma as causalidades próprias de elementos da natureza em causalidade posta (ou seja, submetida às necessidades da finalidade), é que se pode realizar o trabalho.

Aqui é importante destacar o caráter de modelo do trabalho para toda a prática social. A conhecida frase de Marx (2001) em O 18 de Brumário de Luís Bonaparte, segundo quem "os homens fazem a sua própria história; contudo não a fazem de livre e espontânea vontade, pois não são eles quem escolhem as circunstâncias sob as quais ela é feita" (p. 25), pode nos ajudar a dar uma imagem mais robusta dessa prática. Marx está tratando da sociedade como objeto do agir humano, ressaltando que esse agir é limitado pelas condições impostas pelo objeto sobre o qual age o ser humano, nesse caso a sociedade em dado momento histórico. Uma limitação que não é absoluta, o que abre um campo de possibilidades de transformação do objeto em algo diferente do que é no momento; mas que não se trata de possibilidades infinitas, independente das propriedades do objeto - sociedade historicamente contextualizada -, o que deve afastar intenções voluntaristas.

Por seu turno, Lukács (2013) chama a atenção para dois processos heterogêneos entre si, porém indissociáveis, que são fundamentais para a realização da finalidade posta. Um deles, já mencionado, é articular as cadeias causais de acordo com a necessidade posta (e.g. transformar propriedades da pedra em uma propriedade coerente com a satisfação da necessidade, lapidando até ser cortante o suficiente para virar a ponta de um machado e abrir um coco). O outro processo, que é condição para o pôr das cadeias causais, é o espelhamento da realidade da forma mais correta possível. Essa necessidade evidencia uma separação entre objetos da realidade - que existem independentes dos sujeitos - e os sujeitos, que precisam figurar tal realidade em suas consciências, como condição para seu agir teleológico. Se não fosse possível tal reprodução da realidade na consciência, não seria possível a realização de finalidades postas, fundamento do trabalho e de toda práxis humana (Lukács, 2013).

Não se pode, contudo, absolutizar a ação da consciência, como se ela passivamente reproduzisse uma cópia perfeita do que é o real em si mesmo, o que revela a necessidade de instrumentos cada vez mais apurados para a compreensão dos objetos. Mesmo se tratando de graus de conhecimento imperfeitos e até mesmo incorretos em alguma medida, eles podem garantir a realização do fim posto. Além disso, o espelhamento está sempre submetido e guiado pela finalidade, o que significa que nem todas as propriedades intensivas do objeto precisam ser descobertas. Portanto a separação entre sujeito e objeto é algo fulcral para a atividade humana.

No sentido exposto, são necessárias ideias - e podem ser de diversas naturezas - sobre o que o mundo é, para agir sobre ele. Ao conjunto dessas imagens Lukács (2013) chama "ontologia da vida cotidiana", justamente por nos servirem à prática imediata. A complexificação da sociedade, contudo, torna a prática humana cada vez mais mediada, de modo que é ampliada a lacuna entre prática e estruturas sobre as quais agimos. Com isso, noções úteis em um momento podem perder sua função de manipulação da realidade imediata no momento seguinte, possibilitando o aumento da falsidade de tais noções, cada vez mais parciais, e exigindo formulações mais refinadas por parte da filosofia e da ciência (Medeiros, 2013). Ressalte-se que a própria ciência pode, em função de determinações histórico-sociais, ser relegada a um caráter instrumental, manipulatório, e não ir além de tal caráter (Medeiros, 2013), como no caso do formalismo agnosticista.

O que a análise ontológica do trabalho nos ensina é que a separação entre realidade e consciência possibilita buscar as propriedades, conexões etc. daquela para orientar o agir sobre ela mesma, de modo que a consciência se apresenta no início e no fim do processo. A ampliação dessa compreensão - pela ciência - dilata o horizonte prático, aumentando o domínio sobre a realidade e o grau de liberdade humana (sua possibilidade de escolhas conscientes). "Essa capacidade da ciência de conferir aos seres humanos um domínio mais amplo sobre o mundo, natural e social, é em si o seu conteúdo emancipatório" (Medeiros, 2013, p. 101).

Não se trata de assinar embaixo de tudo que é feito em nome da ciência, tampouco de afirmar o caráter absoluto de suas descobertas, mas não podemos negar as possibilidades dadas de domínio da realidade, por exemplo, a partir da revolução copernicana ou da teoria darwiniana. Para efetivar tais conteúdos, a orientação da ciência deve ser a verdade, e esta só pode ser a verdade do objeto. Ou seja, visto que a possibilidade da ação humana se encontra na investigação da realidade, a verdade não pode ser relativa aos sujeitos que conhecem, mas apenas à própria realidade. Nessa direção, tanto é necessário afastar a possibilidade de verdade absoluta - final, imutável e inquestionável - quanto relativista - de que a verdade é uma questão de perspectiva do sujeito ou grupo que olha a realidade.

Consideradas as reflexões ontológicas feitas até aqui, na próxima seção discutiremos suas implicações para as Ciências Sociais e retomaremos a questão da verdade 
e do caráter emancipatório da ciência, aprofundando o argumento.

\section{O social como objeto científico}

Já chamamos a atenção para o alcance da famosa passagem d'O 18 de brumário de Luís Bonaparte, em que Marx aponta a condição posta pela história para o agir humano, cabendo agora explorar mais detidamente a questão do agir humano que toma a sociedade como objeto. Esse imbróglio, que acompanha as Ciências Sociais - incluída a psicologia - desde seu nascimento, pode ser sintetizado em algumas questões: como pesquisar a nós mesmos? É possível ser observador e observado ao mesmo tempo? É possível o conhecimento objetivo de uma realidade produzida por nós mesmos?

Mostramos anteriormente que o mundo precede a ação humana e é sua condição de possibilidade, o que também se aplica ao mundo social. De acordo com Bhaskar (1998), nossa consciência não pode determinar a estrutura do mundo; ao contrário, "é a natureza dos objetos que determina suas possibilidades cognitivas para nós" (p. 206) - o que não significa consciência passiva, como já ressaltado.

Desse argumento é depreendida a necessidade da autonomia relativa das estruturas sociais em relação aos sujeitos, para que seja possível todo agir. Ou seja, como o agir humano não pode partir do nada, ele pressupõe estruturas físicas e sociais, da mesma forma que a fala pressupõe a linguagem, agir como pai/mãe pressupõe a estrutura social familiar, trabalhar pressupõe relações sociais de produção específicas de uma época etc. A sociedade não é conjunto de fenômenos que acessamos pelos sentidos, mas um conjunto de relações - estruturas ou mecanismos - e das relações entre essas relações, além dos fenômenos que se expressam a partir dessas relações (Bhaskar, 1998), um complexo de complexos (Lukács, 2013).

Segundo Bhaskar (1998), a sociedade (suas estruturas) sempre já está feita, pressuposta na ação (assim como na relação com o mundo natural os objetos da realidade são antecedentes à ação sobre eles), e a práxis humana pode apenas modificá-la. Contudo, e isso é um aspecto fundamental, é a totalidade dos atos individuais que mantém ou transforma a sociedade.

Assim, podemos dizer que as estruturas sociais são relativamente autônomas em relação ao agir humano, ainda que não possam dele prescindir, situação que leva Bhaskar (1998) a afirmar uma especificidade ontológica do social. Visto que, como já apontado, o agir humano é consciente e decorre de escolhas entre alternativas, temos que é "restringindo e facultando os atos humanos que a sociedade atua sobre a consecução das posições teleológicas, condicionando-as ... o correto é afirmar que as estruturas sociais impõem limites e estabelecem as possibilidades abertas ao agir humano" (Medeiros, 2013, p. 54). Isso não significa que é possível entender completamente as ações individuais singulares conhecendo as estruturas, mas que, sem conhecer as mediações (das estruturas), não compreendemos o que ocorre no nível dos atos singulares.

Em síntese, e tendo em vista nosso propósito neste trabalho, se a atividade humana é trabalho sobre objetos que existem previamente à própria atividade, a sociedade é, assim, objeto sobre o qual agimos - e assim nos socializamos. Coerente com a reflexão até aqui desenvolvida, para agirmos sobre ela precisamos concebê-la de alguma maneira, de modo que todos os elementos pertinentes à relação entre sujeito e objeto - espelhamento, escolha alternativa - são igualmente válidos para o caso da atuação dos sujeitos sobre o mundo social, o que nos faculta uma ciência sobre o social.

\section{Antiontologismo, antirrealismo e crítica ontológica}

Tendo demonstrado que uma ciência do social é possível, podemos agora enfrentar as questões epistemológicas suscitadas amiúde em face da complexidade desse objeto e, finalmente, mostrar como a análise ontológica permite superar os entraves colocados. Isso porque a maior parte das tradições epistemológicas, ao longo do desenvolvimento das ciências modernas, justamente como expressão da "decadência ideológica", seguiu uma tendência antiontológica (Lukács, 2012).

Dado o entendimento de que tudo que não diga respeito à dimensão empírica não passa de metafísica, o positivismo (e o chamado pós-positivismo) achata a realidade, traduzindo o que Bhaskar (1998) chama de realismo empírico. A prática científica, nessas condições, é reduzida a uma manipulação generalizada da realidade imediata (empírica). Sob a ótica positivista, a forma como se apresentam os dados da realidade humana em determinado momento é "entificada" como aquilo que a realidade realmente é, afastando-se, dessa forma, o caráter dinâmico do real - garantido pelo próprio fato de sua historicidade e de suas estruturas transempíricas. O papel da ciência, assim, seria identificar padrões de conexões entre eventos e elaborar modelos explicativos, abstrações, que correspondam à realidade como tal.

Por seu turno, as concepções da atividade científica que buscaram enfrentar ou superar os limites do positivismo, em sua maioria, o fizeram por um caminho relativista (em graus diferentes, é bem verdade) que, em última instância, redunda em uma ontologia empírica (Duayer, 2016). O "relativismo no atacado" (Duayer, 2015) inclui tanto tradições pós-modernas, pós-estruturalistas e neopragmáticas como as filosofias da ciência de Thomas Kuhn (1998), Imre Lakatos e Paul Feyerabend (para citar somente os nomes mais conhecidos).

Embora não seja objetivo deste texto analisar cada uma das concepções apresentadas, ressaltamos que o elemento em comum entre elas está no fato de considerarem que o conhecimento do mundo jamais pode ser objetivo, pois sempre parte de um ponto de vista, alguma forma de 
consenso local - de grupo científico, classista, cultural, geográfico, étnico etc. (Duayer, 2015). Trata-se de uma postura típica do irracionalismo (Lukács, 2020). Portanto tais concepções implicitamente acabam secretando uma ontologia empirista, uma vez que o mundo passa a ser aquilo que sujeitos ou grupos sociais percebem - e, à percepção imediata, o que aparece é o mundo empírico.

As críticas ao positivismo formuladas pelas concepções sobre a atividade científica referidas questionam seu pressuposto de que o conhecimento científico é neutro e, por isso, verdadeiro. Contudo, ao apontarem a relatividade de nossas crenças, científicas inclusive, seguem por um caminho em que acabam por equiparar os diversos tipos de crença em todos os seus termos. Nessa direção, quaisquer formulações teóricas visando superar a realidade imediata que refletem, que busquem ser verdadeiras para outras relações que não o contexto imediato, são logo acusadas de totalizantes e, numa ilação lógica preocupante e recorrente, totalitárias (Duayer, 2015). Eis o que está em jogo no "combate às grandes narrativas" em voga.

Vale salientar que o problema no relativismo não está exatamente na suposição - correta - de que o conhecimento é histórico. Algumas tradições, de fato, tentam historicizar a atividade humana e o conhecimento, mas o fazem sem um lastro ontológico, por isso recaindo em uma falácia epistêmica (Bhaskar, 2008). Ao considerarem o caráter transitório e social do conhecimento, negam a realidade do objeto independente do sujeito que o conhece, assumem "que questões ontológicas sempre podem ser transpostas em termos epistemológicos" (Bhaskar, 2008, p. 29).

Essa é a postura que tem sustentado o antropocentrismo na filosofia da ciência (Bhaskar, 2008), colocando o sujeito do conhecimento no centro do processo, afastando a própria realidade sobre a qual o sujeito precisa se indagar. Consoante com o que analisamos acerca do trabalho humano e sua relação com a reflexão sobre o mundo (tanto o espelhamento quanto a escolha alternativa), afirma Collier (1994) que "o conhecimento existe como um aspecto do nosso ser no mundo, e antes de podermos saber como sabemos, precisamos ter alguma ideia sobre como interagir com aquele mundo de tal modo que adquiramos conhecimento dele" (p. 137).

O antropocentrismo leva à dedução de um relativismo ontológico a partir do relativismo epistemológico. Como não existiria a realidade independente do conhecimento dela, todas as ontologias (figurações da realidade) são equiparáveis. Logo, como apontado no início deste texto, não podem ser comparadas nem criticadas, operando um “relativismo julgamental" (Duayer, 2015).

Uma das ideias centrais desse antiontologismo e, podemos agora dizer, antirrealismo é o receio da palavra essência (ontologia). No enfrentamento à metafísica, várias tradições negaram quaisquer possibilidades de pensar o fundamento dos fenômenos. Vejamos uma preciosa passagem Foucaultiana sobre tal procedimento:
Ora, se o genealogista tem o cuidado de escutar a história em vez de acreditar na metafísica, o que é que ele aprende? Que atrás das coisas há, "algo inteiramente diferente": não seu segredo essencial e sem data, mas o segredo que elas são sem essência, ou que sua essência foi construída peça por peça a partir de figuras que lhe eram estranhas. (Foulcault, 1978, p. 18, grifo nosso)

Nessa compreensão, toda ontologia é, tal qual no positivismo, relegada ao caráter de pura metafísica, nesse caso como artifício moral. Para o autor, ou por trás das coisas, não há qualquer essência ou "alguém" construiu tal essência, pois ela mesma não pertence à coisa, lhe é "estranha".

Em caminho diverso, sustentamos que uma concepção ontológica, aquela que busca ir além da realidade imediata, não só é possível como é condição para a ciência. "Toda ciência seria supérflua se a forma de manifestação e a essência das coisas coincidissem imediatamente", sintetizou Marx (2017, p. 880), ao mostrar que a economia vulgar nascente em sua época e dominante atualmente - "não faz mais que interpretar, sistematizar e louvar doutrinariamente as concepções dos agentes presos dentro das relações burguesas de produção" (p. 880).

O que a ciência deve possibilitar é ultrapassar o véu que esconde suas estruturas, ainda que essência não deva ser concebida como a verdade escondida sob o véu da esfera mentirosa fenomênica, como faz crer o comentário de Foucault. Essência, aqui, só pode ser concebida se articulada às suas manifestações fenomênicas, tão verdadeiras quanto ela mesma, e por uma maior permanência em relação aos fenômenos manifestos (por exemplo, a estrutura familiar existe, mesmo se certas famílias singulares deixarem de existir fenomenicamente).

Em um investimento ainda mais agressivo na direção do relativismo, há a negação de qualquer possibilidade de conhecimento objetivo e, por consequência, de conhecimento verdadeiro. Nessa direção, como o conhecimento da realidade em si é vedado, os conhecimentos se tornam regimes discursivos ou relações de força em disputa, com igual estatuto. Não é à toa que Deleuze (2011), autor de inspiração nietzschiana e expressão contundente do irracionalismo próprio da crise capitalista a partir do final dos anos 1960, enfatiza uma frase de Paul Valéry: "o mais profundo é a pele", numa clara defesa de que não há nada que se buscar "além" (p. 11).

Contudo as coisas vão exatamente para o caminho contrário das crenças relativistas, de modo que é justamente a afirmação da objetividade do conhecimento que nos faculta a crítica (Bhaskar, 2008). A objetividade do conhecimento não significa, de maneira alguma, neutralidade da ciência (não está aqui o desacordo com a crítica das concepções relativistas ao positivismo). Não se nega que valores interfiram no conhecimento e o conhecimento nos valores sociais (Löwy, 2000); o exercício científico como necessariamente crítico não pode ser neutro. Mas disso não deriva a impossibilidade da ciência 
representar corretamente objetos da realidade, social inclusive, como pressupõe o relativismo. "Alcançando a essência do objeto, isto é: capturando a sua estrutura e dinâmica, por meio de procedimentos analíticos e operando a sua síntese, o pesquisador a reproduz no plano do pensamento" (Paulo Netto, 2011, p. 22). Essa busca pela real constituição do mundo, físico ou social, implica pôr valores alternativos, opor concepções mais verdadeiras às menos verdadeiras, que melhor representem o mundo. E não há nada de metafísico nisso.

Além disso, descobertas científicas geram efeitos sobre valores sociais, contestando ou dissolvendo certas crenças (Medeiros, 2013); ressaltamos a revolução copernicana como um enfrentamento de ontologias (científica versus religiosa) e, necessariamente, de valores. Excluir a pretensão de neutralidade não nega a possibilidade do conhecimento objetivo e, nesse sentido, a instância de verificação da verdade de uma reprodução da realidade (teoria) é a prática social e histórica (Paulo Netto, 2011).

Vale lembrar que um correto espelhamento do mundo não é moral, mas uma necessidade da práxis humana, sem a qual não haveria trabalho, fundamento do ser social. Justamente por isso a ciência deve ser crítica: uma atividade que oponha concepções a outras, de modo que conceber a objetividade do conhecimento seja critério da crítica. E a objetividade aqui se coloca em contraponto à idealização, à ideia de que o mundo social é o que aceitamos ou cremos que seja. Reconhecer diferentes sistemas categoriais, de figuração de mundo e de procedimentos (paradigmas) é apenas o procedimento inevitável em face do convívio no meio científico. O procedimento crítico é submeter a escrutínio a concepção de mundo que subjaz às categorias do sistema, as condições de sua gênese e função social (Lukács, 2020). "Trata-se, enfim, de uma crítica ontológica” (Duayer, 2015, p.150).

É o que permite identificar e enfrentar mistificações, conhecimentos reificados e manipulatórios, cujo papel ideológico se torna fundamental para a reprodução das relações dominantes. Nesse sentido, o movimento de relativizar a realidade ou de negar o papel fundamental da razão no desvelamento do movimento do real, sugerindo que o real é questão de perspectivas singulares, intuitivamente apreendido, parece desconhecer que o "comando" da realidade social continua sendo condicionado pela manipulação da verdade objetiva sobre tal realidade. O que fez e ainda faz o positivismo se impor no campo epistemológico não é uma questão apenas de força, mas o fato de ele ser considerado a forma epistemológica suficiente para a apreensão e manipulação de objetividades imediatas dessa sociedade, uma expressão do agnosticismo. O relativismo perspectivista de caráter irracionalista coloca o problema da dominação como se fosse um problema do conhecimento, da consciência de quem conhece, do conhecimento "situado", quando se trata, em verdade, de um problema relativo à objetividade real - sendo as consciências e conhecimentos mistificadores condicionados por essa mesma objetividade. Trata-se de uma revolta contra a realidade que foge à própria realidade.

Assim, defendemos que explicar como o mundo funciona é, necessariamente, criticar concepções vigentes. Desmistificar formas de consciência a partir da apreensão correta de aspectos da realidade é o "conteúdo subversivo da ciência" (Medeiros, 2013, p. 79). O conhecimento correto das estruturas da realidade e de suas cadeias causais potencializa a prática humana na direção de um grau maior de liberdade, permite aos seres humanos um domínio cada vez mais amplo sobre o mundo.

Por fim, reforçando esse potencial emancipatório e o valor de verdade da ciência, deve-se destacar justamente sua conexão com a realidade. A ciência (social incluída) trata do que a realidade é. No caso das Ciências Sociais, pelo caráter histórico de seu objeto, as teorias jamais podem ser preditivas e definitivas, mas apenas explanatórias, buscando explicar a natureza, as estruturas que condicionam os fenômenos sociais e indicando legalidades que se apresentam como tendências num certo contexto histórico-social. Uma teoria com maior poder explanatório (ou maior capacidade crítica) deve ser capaz de: (a) demonstrar a falsidade das teorias ou crenças criticadas; (b) apresentar uma explicação alternativa mais abrangente para os fenômenos abordados pela teoria criticada; e (c) indicar as condições para a produção e sustentação das concepções criticadas (Medeiros, 2013).

Este último elemento é fundamental para nosso argumento, uma vez que consideramos a possibilidade de teorias equivocadas informarem práticas concretas e imediatas. Assim, criticar certas concepções é "criticar qualquer ação informada ou prática sustentada por tal crença ou teoria" (Bhaskar, 1998, p. 243). Dito de outra maneira, a crítica teórica é a crítica dos objetos ou relações objetivas que fazem de certas concepções, crenças, objetividades socialmente necessárias (ainda que falsas). Assim, como afirma Bhaskar (1998), "uma vez feito isso, teremos feito tudo que a ciência isoladamente pode fazer pela sociedade ou pelas pessoas. E a questão se converte em transformá-los" (p. 243).

\section{Considerações finais: a psicologia e a crítica ontológica}

Tendo em vista a discussão acima desenvolvida, consideramos que é justamente a partir da concepção de sujeito que embasa as diferentes escolas da psicologia que deve se dar a análise ontológica da área, tanto porque essa concepção implica as características da produção de conhecimento quanto porque daí são derivadas as propostas ou os modelos de exercício profissional. Contudo vemos que, ao invés de se perguntar sobre "o que é o sujeito", a psicologia tem se desenvolvido em torno da questão de "como conhecer o sujeito".

Em 1862, Wundt apresentou seu programa de uma psicologia científica, expressão da necessidade que 
identifica de operar uma reforma radical na psicologia, notadamente nos métodos de investigação, consoante com as Ciências Naturais. Assim, defendia ele que questões sobre a natureza e a origem da alma não deveriam ser preocupação da psicologia, visto não poderem ser tratados cientificamente. Assim, em que pese grande avanço técnico e metodológico, a dispersão teóricoconceitual observada atualmente revela que "não fizemos qualquer progresso em relação às suas questões básicas - no sentido de ao menos caminhar em direção a um consenso mínimo sobre seus fundamentos filosóficos" (Tweney \& Budzynski, 2000 citados por Araújo, 2007, p. 26). De acordo com Araújo (2007), foi Wundt, "mais do que qualquer outro, que lutou para estabelecer um novo modelo de psicologia, guiado primeiramente por uma reforma metodológica radical, que buscava romper os laços tradicionais com a especulação metafísica, visando a uma aproximação com as ciências naturais" (p. 27).

Para efeito deste artigo, não cabe análise da evolução teórico-epistemológica de Wundt, mas tão somente sinalizar os elementos que demarcam seu compromisso com a construção de uma teoria geral do conhecimento, ou "antiontologismo", de matiz gnosiológico, adotada como fundamento do seu projeto de psicologia. Nesta direção, é importante sua afirmação de que

a teoria do conhecimento tem que descrever não o desenvolvimento histórico, mas sim o desenvolvimento lógico do conhecimento. Ela consiste essencialmente, portanto, em uma aplicação das leis lógicas do pensamento tanto à gênese psicológica de nossos conceitos de mundo quanto ao desenvolvimento histórico do conhecimento científico do mundo. (Wundt, 1889 citado por Araújo, 2007, p. 165)

Ao se negarem à discussão a respeito da concepção de sujeito que subjaz às concepções de objeto e de método, as psicologias aprofundam as divergências a tal ponto que, no campo da filosofia da ciência, não resta outra alternativa senão assumir a perspectiva paradigmática, com suas já evidenciadas implicações de caráter irracionalista e relativista, ou se apoiar em um "mimetismo cientificista" (Martin-Baró, 1986/2011), que tem como modelo o método das Ciências Naturais e funda uma unidade na diversidade em uma forma de apologética da ordem do capital.

Por outro lado, na medida em que se defende que o objeto da psicologia é o ser humano e se entende que ele é histórico e social, o conhecimento produzido a respeito dele somente leva a bom termo se o método para tal é amparado por uma perspectiva ontológica. Nessa direção, o aprofundamento da análise requer, necessariamente, desvelar a concepção de ser humano que subjaz às diferentes escolas da psicologia e criticálas tendo em vista o sujeito concreto com o qual se lida nos diferentes contextos sociais.

É a crítica ontológica, ou seja, aquela que enfrenta as figurações de mundo presentes em diferentes concepções - e as próprias relações que sustentam tais figurações como socialmente necessárias -, como a do ser social, que permite superar tanto o caráter instrumental quanto relativista da ciência social - psicológica incluída -, a fim de desenvolver seu potencial emancipatório. Tal potencial, reafirmamos, não substitui a ação política, sendo em si mesmo uma ferramenta dessa ação. Tem como horizonte o desvelamento da realidade, de sua objetividade em processo, facultando aos humanos uma prática informada e transformadora. Desmistificar a realidade imediata, bem como as concepções que legitimam e naturalizam tal realidade é papel de qualquer ciência social, como é o caso da psicologia. Por esse motivo, a psicologia não pode prescindir da crítica às concepções de sujeito que subjazem às suas distintas vertentes. É condição necessária, ainda que não suficiente, de uma ciência de conteúdo emancipatório.

A partir da análise dessa forma específica de ser, pretendemos demonstrar que a negação da ontologia é uma característica que une o positivismo a várias correntes epistemológicas que buscam criticá-lo/superá-lo. A pergunta, então, que nos orienta neste percurso é: como uma concepção ontológica do ser humano e da

sociedade pode iluminar a prática científica na psicologia? Dito de outra maneira, como a discussão ontológica pode tirar a psicologia do impasse em que se encontra?

\section{Psychology and ontology: foundations for a critical reflection on knowledge production}

Abstract: This article aims to problematize the scientific practice in psychology, presenting theoretical elements that enable an ontological critique of this field. This study was motivated by the understanding that the production of psychological knowledge lacks an ontological conception of society, human action, and knowledge production, thus subordinating the investigation and the debate around the individual about which such knowledge is concerned. This issue ends up by intensifying divergences 
regarding object and method among the different schools of psychology, requiring further in-depth analyses to unveil and criticize the conception of human being that underlies each school while considering the concrete subject dealt with in the different social contexts.

Keywords: science, ontology, psychology.

\section{Psychologie et ontologie : fondements d'une réflexion critique sur la production de la connaissance}

Résumé : Nous discutons la pratique scientifique en psychologie et présentons des éléments théoriques qui permettent une critique ontologique de ce domaine. Nous considérons que la production de connaissances psychologiques manque d'une conception ontologique de la société, de l'action humaine et de la production de la connaissance, mettant de côté l'investigation et le débat sur ce qu'est l'être même sur lequel cette connaissance se concentre. On conclut en affirmant qu'une telle posture a pour conséquence d'approfondir les divergences entre les différentes écoles de psychologie, notamment d'objet et de méthode, et qu'il est nécessaire d'approfondir l'analyse afin de dévoiler la conception d'être humain qui sous-tend les différentes écoles, en la critiquant au regard du sujet concret qu'elle traite dans différents contextes sociaux.

Mots-clés: science, ontologie, psychologie.

\section{Psicología y ontología: elementos para una reflexión crítica sobre la producción de conocimiento}

Resumen: En este texto, problematizamos la práctica científica en la psicología y presentamos elementos teóricos que posibilitan una crítica ontológica a ese campo. Consideramos que falta a la producción de conocimiento psicológico una concepción ontológica sobre la sociedad, la acción humana y la producción de conocimiento, subordinando la investigación y el debate acerca de lo que es el propio ser sobre el cual el conocimiento se centra. Concluimos que tal postura da como resultado la profundización de divergencias entre las diferentes escuelas de psicología, de objeto y de método, y que es necesario profundizar el análisis en el sentido de desvelar la concepción de ser humano que subyace a las diferentes escuelas,

criticándola al considerar el sujeto concreto con el que lidia en los diferentes contextos sociales.

Palabras clave: ciencia, ontología, psicología.

\section{Referências}

Araujo, S. F. (2007). A fundamentação filosófica do projeto de uma psicologia científica de Wilhelm Wundt [Tese de doutorado]. Universidade Estadual de Campinas, Campinas, SP.

Bhaskar, R. (1998). Societies. In M. Archer, R. Bhaskar, A. Collier, T. Lawson, \& A. Norrie (Orgs.), Critical realism: essential readings (pp. 206-257). London: Taylor \& Francis.

Bhaskar, R. (2008). A realist theory of Science. London: Routledge.

Collier, A. (1994). Critical realism: an introduction to Roy Bhaskar's philosophy. London: Verso.

Cornejo, A. (2005). Las dos culturas de/en la psicologia. Revista de Psicología, 14(2), 189-208.

Coutinho, C. N. (2010). O estruturalismo e a miséria da razão. São Paulo, SP: Expressão Popular.

Deleuze, G. (2011). A lógica do sentido. São Paulo ,SP: Perspectiva.
Duayer, M. (2015). Antirrealismo e absolutas crenças relativas. In F. F. Miranda \& R. D. Monfardini (Orgs.), Ontologia e estética (pp. 91-115). Rio de Janeiro, RJ: Consequência.

Duayer, M. (2016). Capital: a verdade absoluta do ceticismo pós-moderno e adjacências. In I. F. Oliveira, I. L. Paiva, A. L. Costa, F. C. Lima, \& K. Amorim (Orgs.), Marx hoje: pesquisa e transformação social (pp. 137-152). São Paulo, SP: Outras Expressões.

Figueiredo, L. C. M. (2008). Matrizes do pensamento psicológico. Petrópolis, RJ: Vozes.

Foucault, M. (1978). Microfisica do poder. Rio de Janeiro, RJ: Graal.

Kuhn, T. (1998). A estrutura das revoluções cientificas (5a ed.). São Paulo, SP: Perspectiva.

Lacerda, F., Jr. (2010). Psicologia para fazer a crítica? Apologética, individualismo e marxismo em alguns projetos psi [Tese de doutorado]. Pontifícia Universidade Católica de Campinas, Campinas, SP.

Löwy, M. (2000). As aventuras de Karl Marx contra o Barão de Münchhausen: marxismo e positivismo na sociologia do conhecimento. São Paulo, SP: Cortez.

Lukács, G. (2012). Para uma ontologia do ser social I. São Paulo, SP: Boitempo.

Lukács, G. (2013). Para uma ontologia do ser social II. São Paulo, SP: Boitempo. 
Lukács, G. (2018). Introdução a uma estética marxista: sobre a particularidade como Categoria da Estética. São Paulo, SP: Instituto Lukács.

Lukács, G. (2020). A destruição da razão. São Paulo, SP: Instituto Lukács.

Martín-Baró, I. (2011). Para uma psicologia da libertação. In R. S. L. Guzzo \& F. Lacerda Jr. (Orgs.), Psicologia social para América Latina: o resgate da psicologia da libertação (pp. 181-198). Campinas, SP: Alínea. (Trabalho original publicado em 1986)
Marx, K. (2011). O 18 de Brumário de Luís Bonaparte. São Paulo, SP: Boitempo.

Marx, K. (2013). O capital: crítica da economia políticaLivro I. São Paulo, SP: Boitempo.

Marx, K. (2017). O capital: crítica da economia política Livro III. São Paulo, SP: Boitempo.

Marx, K., \& Engels, F. (2007). A ideologia alemã. São Paulo, SP: Boitempo.

Medeiros, J. L. (2013). A economia diante do horror econômico: uma crítica ontológica dos surtos de altruísmo da ciência econômica. Niterói, RJ: Editora da UFF.

Paulo Netto, J. (2011). Introdução ao estudo do método de Marx. São Paulo, SP: Expressão Popular.

Shuare, M. (2017). A psicologia soviética: meu olhar. São Paulo, SP: Terracota.

Vygotski, L. S. (2013). Obras escogidas - I: el significado histórico de la crisis de la Psicología. Madrid: Machado Livros.

Recebido: 30/04/2021

Aprovado: 25/06/2021 